\title{
Electrophoretic Deposition of Antimonene for Photoelectrochemical Applications
}

Jesús Barrio, ${ }^{\mathrm{a}}$ Carlos Gibaja, ${ }^{\mathrm{b}}$ Miguel García-Tecedor, ${ }^{\mathrm{c}}$ Liel Abisdris, ${ }^{\mathrm{a}}$ Iñigo Torres, ${ }^{\mathrm{b}}$ Neeta Karjule, ${ }^{\mathrm{a}}$ Sixto Giménez, ${ }^{\mathrm{c} *}$ Menny Shalom, ${ }^{\mathrm{a}^{*}}$ Félix Zamora. ${ }^{\mathrm{b}, \mathrm{d}^{*}}$

a Department of Chemistry and Ilse Katz Institute for Nanoscale Science and Technology, Ben-Gurion University of the Negev, Beer-Sheva 8410501, Israel

${ }^{\text {b}}$ Departamento de Química Inorgánica, Institute for Advanced Research in Chemical Sciences, Universidad Autónoma de Madrid, Madrid 28049, Spain

${ }^{\mathrm{c}}$ Institute of Advanced Materials (INAM), Universitat Jaume I, 12006 Castello, Spain.

${ }^{\mathrm{d}}$ Instituto Madrileño de Estudios Avanzados en Nanociencia (IMDEA-Nanociencia), Cantoblanco, E-28049 Madrid, Spain.

Keywords: antimonene, liquid phase exfoliation, electrophoretic deposition, titanium dioxide, photoelectrochemical cells.

\begin{abstract}
Antimonene is a recently developed two-dimensional material with outstanding expected physical properties based on theoretical calculations. Liquid phase exfoliation has become the most straight forward preparation method to produce stable antimonene suspensions. However, the processing and deposition on substrates of antimonene that is still required towards its exploitation in various fields, as current challenges in this research area. Despite the high current research interest in antimonene, the fabrication of Sb-films and its utilization in photoelectrochemical devices remains still unexplored. Herein, the electrophoretic deposition of antimonene on different substrates and its activity as absorber and hole acceptor layer in photoelectrochemical cell (PEC) is reported. The obtained results confirm that the photoelectrochemical performance of the antimonene films electrophoretically deposited on titanium dioxide exhibits an enhanced optical absorption and charge separation properties, compared to pristine $\mathrm{TiO}_{2}$ films. Furthermore, electrochemical measurements reveal that the antimonene films acts as a hole acceptor layer, enabling better PEC performance.
\end{abstract}




\section{Introduction}

Two-dimensional (2D) materials have gathered a lot of attention during the last decade since the isolation and exploitation of graphene due to the peculiar properties derived from nanosized effects [1]. A wide variety of 2D materials have been reported and applied in different fields e.g. transition metal dichalcogenides (TMDCS), metal carbides (MXenes) [2,3], metal-free carbon- and boron nitride [4,5], and monoelemental ones (Xenes) such like graphene or phosphorene to name a few [6,7]. In this context, a new monoelemental 2D material that has recently gained a lot of attention is the so-called antimonene (2D-Sb). As phosphorene, this $2 \mathrm{D}$ material is another pnictogen that has been isolated as monolayer or few-layers (FL) by several methods including mechanical [8], liquid-phase (LPE) or electrochemical exfoliation,[9] as well as epitaxial growth [10,11]. Antimonene has been widely investigated due to its high stability under ambient conditions and their predicted physical properties such as strong spinorbit coupling, topological properties or its low band gap suitable for optoelectronic applications $[12,13]$. However, despite the recent progress in the theoretical and experimental investigations of 2D-Sb [14], and its application as supercapacitor [15], catalyst for organic reactions [16], electrocatalyst for hydrogen evolution reaction (HER) [17,18], or biosensing $[19,20]$, the fabrication of Sb-films and its utilization in photoelectrochemical devices remain still unexplored. Here, we demonstrate the deposition of 2D-Sb layers over conductive substrates by electrophoretic deposition (EPD) and its activity as absorber and hole acceptor layer in a photoelectrochemical cell (PEC). The morphology of the 2D flakes is thoroughly characterized as well as the physical and electronic features of the films. We further explored the deposition of 2D-Sb on mesoporous $\mathrm{TiO}_{2}$ as well as its photoelectrochemical performance. The new $\mathrm{Sb}-\mathrm{TiO}_{2}$ film exhibits an enhanced optical absorption and charge separation properties, compared to pristine $\mathrm{TiO}_{2}$ films. Electrochemical measurements reveal that the 2D-Sb mainly acts as a hole acceptor layer, enabling better PEC performance. 


\section{Experimental Section}

\subsection{Preparation of 2D-Sb}

This procedure involves a pre-grinding process of the Sb crystals (Smart Elements, 99.9999\% purity) with an agate mortar resulting in so-called ground Sb. After the grinding process, a stainless-steel reactor with a volume of $5 \mathrm{~mL}$ (Retsch 1.4112) was filled under ambient conditions with $300 \mathrm{mg}$ of ground Sb powder, 3 stainless steel balls of $4.74 \mathrm{~mm}$ diameter and $0.5 \mathrm{~mL}$ of butan-2-ol (99.5\%, Sigma Aldrich). Subsequently, the samples were milled for 120 min at $30 \mathrm{~Hz}$ in a Retsch MM 400 mixer mill. After milling, the reactors were washed with butan-2-ol to obtain all the grey metallic Sb paste, which was then centrifuged at $13000 \mathrm{rpm}$ for $30 \mathrm{~min}$. The deposited $\mathrm{Sb}$ was dried on a hot plate at $100{ }^{\circ} \mathrm{C}$ for 12 hours and for another 24 hours in a drying oven at $75^{\circ} \mathrm{C}$ and a few mbar. A colloidal dispersion of $2 \mathrm{D}-\mathrm{Sb}$ was prepared by sonication of $10 \mathrm{mg}$ of ball-milled $\mathrm{Sb}$ in $10 \mathrm{~mL}$ of toluene for $30 \mathrm{~min}, 400 \mathrm{~W}, 24 \mathrm{kHz}$ and at an amplitude of $40 \%$ with a sonication tip. Then, the resulting black Sb suspension was centrifuged at $3000 \mathrm{rpm}$ (746 g) for $3 \mathrm{~min}$, in order to eliminate the non-exfoliated crystals, and the clear supernatant was recovered.

\subsection{Deposition of 2D 2D-Sb on FTO substrates}

Electrophoretic deposition (EPD) was carried out with an ENDURO ${ }^{\mathrm{TM}}$ Power supplies system operated at $300 \mathrm{~V}$ and different deposition times (1 to $3 \mathrm{~min}$ ), and a colloidal dispersion of $\mathrm{Sb}$ $\left(1 \mathrm{mg} \mathrm{mL}^{-1}\right)$ in tholuene previously sonicated for $30 \mathrm{~min}$ at $40 \%$ amplitude with a sonication tip. Following the EPD, the electrodes were annealed for $1 \mathrm{~h}$ at $300^{\circ} \mathrm{C}$ for improving the contact between the material and the substrate. $\mathrm{TiO}_{2}$-coated FTO electrodes were prepared by doctor blading a transparent paste of $\mathrm{TiO}_{2}$, with $20 \mathrm{~nm}$ particle size over clean FTO electrodes, followed by annealing at $450{ }^{\circ} \mathrm{C}$ for 30 min under air. $\mathrm{Sb}$ was then deposited over $\mathrm{TiO}_{2}$ electrodes by EPD during $3 \mathrm{~min}$ at $300 \mathrm{~V}$ followed by thermal annealing under air for $1 \mathrm{~h}$ at $300{ }^{\circ} \mathrm{C}$ 


\subsection{Characterization}

AFM measurements were carried out using a Cervantes Fullmode AFM from Nanotec Electronica SL. WSxM software (www.wsxmsolutions.com) was employed both for data acquisition and image processing [21]. PPP-NCHR cantilevers (nanosensors.com) with a nominal spring constant of $42 \mathrm{~N} \cdot \mathrm{m}^{-1}$ and tip radius of less than $7 \mathrm{~nm}$ were employed. The tapping mode was used for imaging to ensure that the nanolayers would not be damaged by the tip [22]. Raman spectra were acquired on a LabRam HR Evolution confocal Raman microscope (Horiba) equipped with an automated XYZ table using 0.80 NA objectives. All measurements were conducted using an excitation wavelength of $532 \mathrm{~nm}$, with an acquisition time of $5 \mathrm{~s}$ and a grating of 1800 grooves per mm. To minimize photo-induced laser oxidation of the samples, the laser intensity was maintained at $10 \%(1.6 \mathrm{~mW})$. TEM images were obtained on a JEOL JEM 2100 FX TEM system with an accelerating voltage of $200 \mathrm{kV}$. The microscope has a multiscan charge-coupled device (CCD) camera (ORIUS SC1000) and an OXFORD INCA Xray XEDS microanalysis system. SEM analysis of the 2D-Sb nanolayers was performed using a Philips XL 30 S-FEG microscope operating at an accelerating voltage of $10 \mathrm{kV}$. X-ray diffraction patterns (XRD) of the synthesized powders were obtained using an Empyrean powder diffractometer (Panalytical). Ultraviolet-visible spectroscopy (UV-Vis) spectra were collected using a Cary 100 spectrophotometer. XPS data were obtained with an X-ray photoelectron spectrometer ESCALAB 250 ultrahigh vacuum $\left(1 \times 10^{-9}\right.$ bar $)$ device with an $\mathrm{Al}$ $\mathrm{K} \alpha \mathrm{X}$-ray source and a monochromator. The X-ray beam size was $500 \mu \mathrm{m}$, survey spectra were recorded with a pass energy (PE) of $150 \mathrm{eV}$ and high energy resolution spectra were recorded with a PE of $20 \mathrm{eV}$. To correct for charging effects, all spectra were calibrated relative to a carbon $\mathrm{C} 1 \mathrm{~s}$ peak, positioned at $284.8 \mathrm{eV}$. The depth profile of the sample was obtained by combining a sequence of Ar ion gun etch cycles interleaved with XPS measurements from the current surface. The sputtering rate was approximately $0.07 \mathrm{~nm} \cdot \mathrm{s}^{-1}$. The XPS results were 
processed by using the AVANTGE software. Surface profile measurements were performed by a laser microscope LEXT OLS5000 under low magnification. The photoelectrochemical performance of the electrodes was evaluated in the dark and under illumination in a threeelectrode cell consisting of a working electrode, an $\mathrm{Ag} / \mathrm{AgCl}(3 \mathrm{M} \mathrm{KCl})$ reference electrode, a Pt foil as a counter electrode and $0.1 \mathrm{M} \mathrm{KOH}, 0.5 \mathrm{M} \mathrm{H}_{2} \mathrm{SO}_{4}$ and $0.1 \mathrm{M} \mathrm{Na}_{2} \mathrm{SO}_{4}$ as electrolytes. The measurements were carried out by using two Autolab potentiostat/galvanostat Metrohm, PGSTAT101 and PGSTAT302, and a $300 \mathrm{~W}$ Xe lamp was used for those experiments under illumination conditions. The light intensity was adjusted to $100 \mathrm{~mW} / \mathrm{cm}^{2}$ using a thermopile and illumination was carried out through the electrolyte. All the potentials were referred to the Reversible Hydrogen Electrode (RHE) through the Nernst equation: $V_{\mathrm{RHE}}=\mathrm{V}_{\mathrm{Ag} / \mathrm{AgCl}}+$ $\mathrm{V}_{\mathrm{Ag} / \mathrm{AgCl}}^{0}+0.059 \cdot \mathrm{pH}$. Incident Photon to Current Efficiency (IPCE) measurements were performed with a $150 \mathrm{~W}$ Xe lamp coupled with a monochromator and an optical power meter. The photocurrent was measured at $1.23 \mathrm{~V}$ vs RHE, with $10 \mathrm{~nm}$ spectral step. IPCE was calculated through the expression: IPCE $\%=\frac{\mathrm{I}_{\mathrm{ph}}(\mathrm{A})}{\mathrm{P}(\mathrm{W})} \times \frac{1239.8}{\lambda(\mathrm{nm})} \times 100$, where $\mathrm{I}_{\mathrm{ph}}$ is the photocurrent measured at a wavelength $\lambda$ and $\mathrm{P}$ is the power of the monochromatic light at the same wavelength. The amount of evolved gas was evaluated by Gas Chromatography (Agilent 7820 GC System). Electrochemical Impedance Spectroscopy (IS) measurements were performed between $50 \mathrm{mHz}$ and $1 \mathrm{MHz}$ with $20 \mathrm{mV}$ of amplitude perturbation, with a step potential of $64 \mathrm{mV}$ in the anodic direction. The IS data were analyzed with ZView software (Scribner associates). With the extracted capacitance values from IS at the anodic region; MottSchottky analysis was carried out using the expression: $\frac{1}{C_{S C}^{2}}=\frac{2}{\varepsilon_{0} \varepsilon_{r} e N_{D} A^{2}}\left(\phi_{S C}-\frac{k T}{e}\right)$, where $C_{S C}$ represents depletion capacitance, $\phi_{S C}=V-V_{F B}$ is the voltage drop at the space charge region, $V$ is the applied voltage, $V_{F B}$ the flat band potential, $N_{D}$ the donor density, $e$ is the elementary charge, $\varepsilon_{0}$ is the permittivity in vacuum, $\varepsilon_{r}$ is the relative permittivity of $\mathrm{TiO}_{2}$, (taken as 50) 
[23], $k$ is the Boltzmann constant and $T$ is the absolute temperature, taken as $298 \mathrm{~K}$. From this analysis, the values of $V_{F B}$ and $\mathrm{N}_{\mathrm{D}}$ were extracted.

\section{Results and Discussion}

\subsection{Materials Preparation and Characterization}

Firstly, we pre-processed the bulk antimony crystals with butan-2-ol using a ball-milling method as described in our previous work [17]. Then, we used the pre-processed antimony crystals to obtain a colloidal dispersion of 2D-Sb by LPE using toluene as solvent (For further details see Experimental Section). The final concentration of the as-prepared dispersions was $0.135 \mathrm{~g} \cdot \mathrm{L}^{-1}$ (measured upon vacuum drying the sample overnight and the obtained solid was weighed to know the exact amount of Sb that was in the sample).

a)

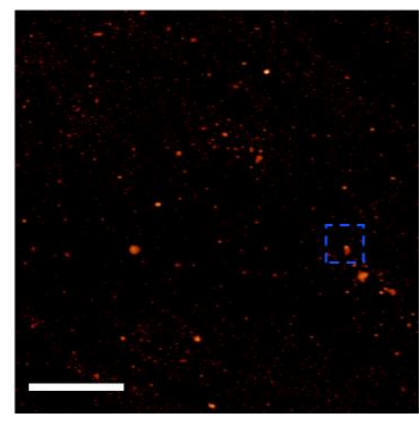

d)

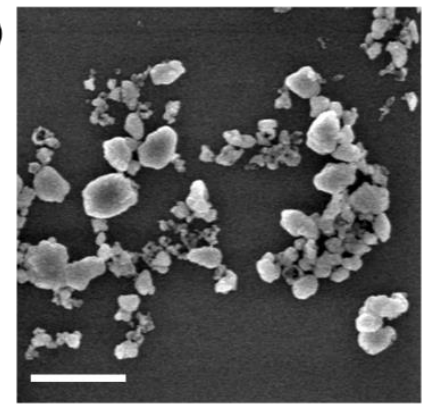

b)

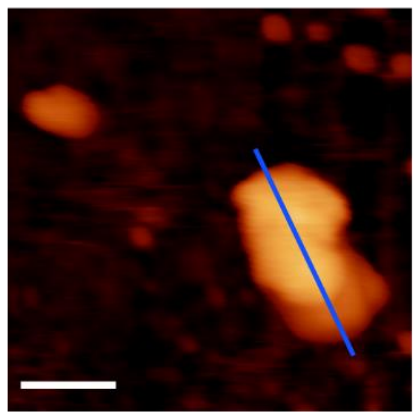

e)

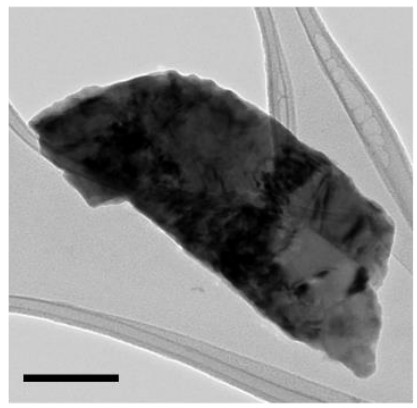

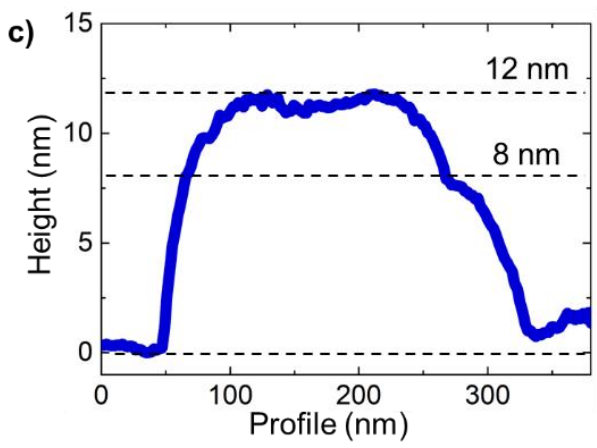

f)

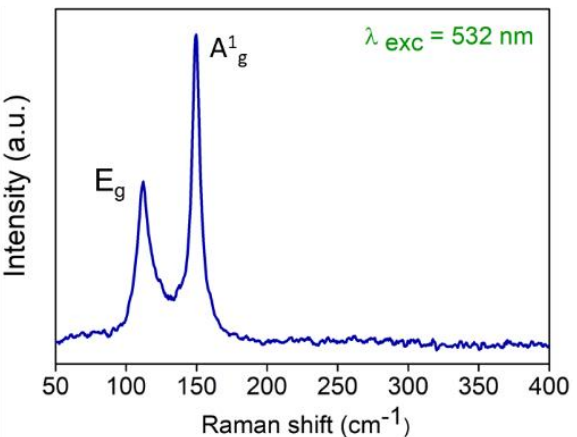

Figure 1. a) Representative topographic AFM image (scale bar $2 \mu \mathrm{m}$ ) of a 2D-Sb nanolayers toluene dispersion drop-casted deposited on $\mathrm{SiO}_{2} / \mathrm{Si}$. b) Magnification of the blue dashed area in (a) showing the typical AFM topographic image of a 2D-Sb nanolayer (scale bar $100 \mathrm{~nm}$ ).

c) Height profile along the blue line in (b). d) SEM image of 2D-Sb nanolayers (scale bar 500 
$\mathrm{nm}$ ). e) TEM image of an isolated 2D-Sb nanolayer (scale bar $100 \mathrm{~nm}$ ). f) Single-point Raman spectrum of the $2 \mathrm{D}-\mathrm{Sb}$ nanolayer showed in (b).

This concentration value is not as high as those previously reported in butan-2-ol, $c a$. 0.368 $g \cdot \mathrm{L}^{-1}[17]$, but suitable for films preparation by LPE. Toluene was selected as solvent instead of the typical alcohols [17] because it is highly suitable for the subsequent electrophoretic deposition step. Besides, using toluene does not affect to the morphological and chemical integrity to the obtained 2D-Sb nanolayers.

Figure 1 shows a summary of the most significant features of a 2D-Sb representative sample. The morphology of the particles contained in the so-formed toluene 2D-Sb dispersion was evaluated using atomic force microscopy (AFM). Figure 1a-c show typical topographic AFM images of $2 \mathrm{D}-\mathrm{Sb}$ nanolayers casted into a $\mathrm{Si} / \mathrm{SiO}_{2}$ substrate that contains isolated nanolayers showing a minimum step height of $c a .4 \mathrm{~nm}$ (Figure 1b-c). A statistical AFM analysis has been also performed on the sample, based on histograms over 150 2D-Sb nanolayers (Figure S1). The histograms show that the mean lateral dimensions (Figure $\mathrm{S} 1 \mathrm{~b}$ ), $\langle\mathrm{L}\rangle$, of most $2 \mathrm{D}-\mathrm{Sb}$ nanolayers is $\sim 378 \mathrm{~nm}$, while the mean height (Figure S1c), $\langle\mathrm{H}\rangle$, is $\sim 22 \mathrm{~nm}$. A closer examination to the results collected in Figure $\mathrm{S} 1$ shows a limiting step height of $c a .4 \mathrm{~nm}$ that corresponds with a lateral dimension of $\sim 209 \mathrm{~nm}$, what perfectly agrees to that previously reported [17]. The ruffled morphology observed by AFM has been further confirmed by electron microscopy measurements using transmission (TEM) and scanning (SEM) modes. Figure 1d and S2 show SEM images of several 2D-Sb nanolayers, and Figure 1e and S3 show TEM images of isolated 2D-Sb nanolayers, all of them with lateral dimensions within the range measured by AFM, ca. 200-400 nm.

To further characterize the sample quality, we have also performed Raman measurements. Figure $1 f$ shows a single point Raman spectrum of a $2 \mathrm{D}-\mathrm{Sb}$ nanolayers deposited on a $\mathrm{SiO}_{2} / \mathrm{Si}$ substrate with a thickness of $c a .12 \mathrm{~nm}$, showed in Figure $1 \mathrm{~b}$, revealing the representative main 
phonon peaks, the $\mathrm{A}_{1 \mathrm{~g}}$ mode at $150 \mathrm{~cm}^{-1}$ and $\mathrm{E}_{\mathrm{g}}$ mode at $110 \mathrm{~cm}^{-1}[10]$. We also performed $\mathrm{X}$ ray energy dispersive spectroscopy (XEDS) measurements in the 2D-Sb nanolayer showed in Figure 1e, corroborating their composition, showing small signals of oxygen (Figure S4).

2D-Sb films were prepared by electrophoretic deposition (EPD) of a $0.135 \mathrm{~g} \cdot \mathrm{L}^{-1}$ toluene suspension of 2D-Sb nanolayers at $300 \mathrm{~V}$ and different time ranges for achieving different coverages thickness, followed by the thermal annealing at $300{ }^{\circ} \mathrm{C}$ for $1 \mathrm{~h}$. Electrophoretic deposition is a very useful technique for the fabrication of homogeneous films of a wide variety of materials, including among others graphitic carbons [24,25], metal-organic frameworks (MOFs) [26,27], covalent organic frameworks (COFs) [28], or inorganic structures [29,30].

a)

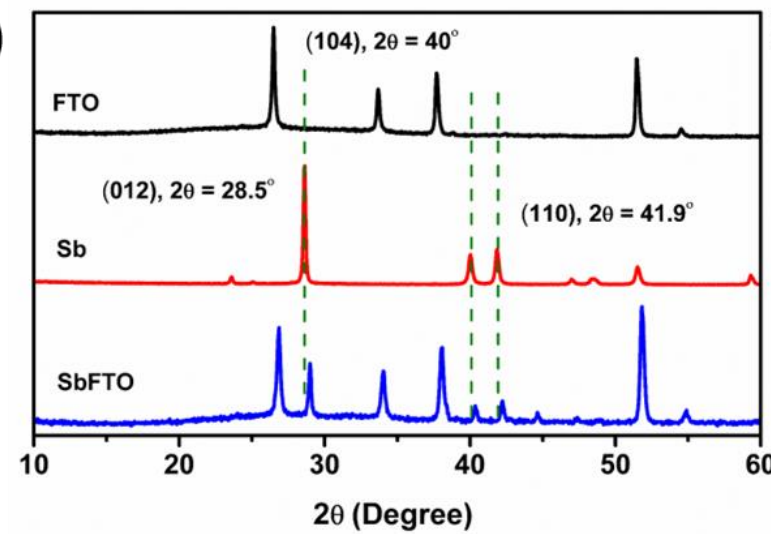

c)

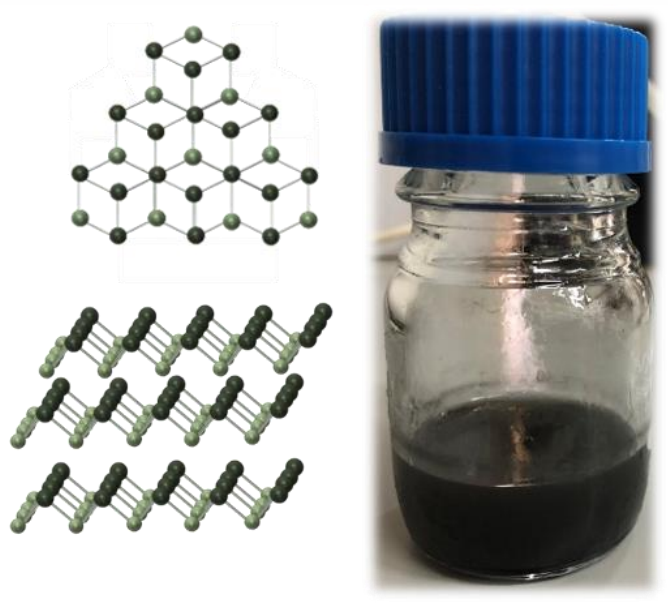

b)

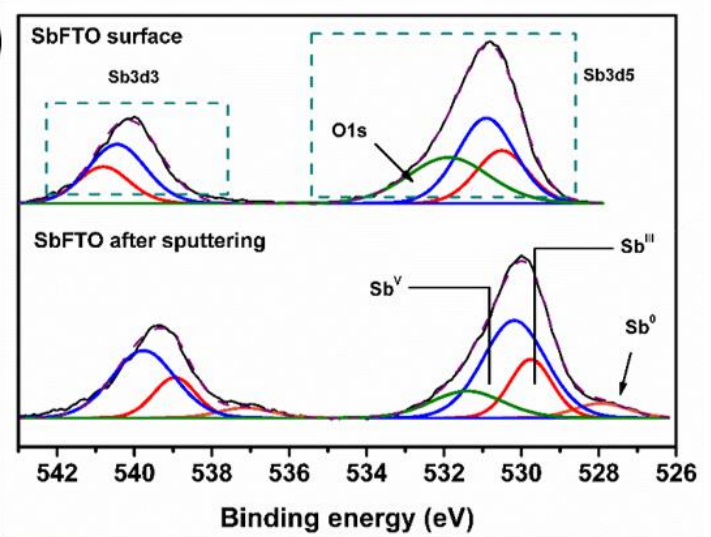

d)

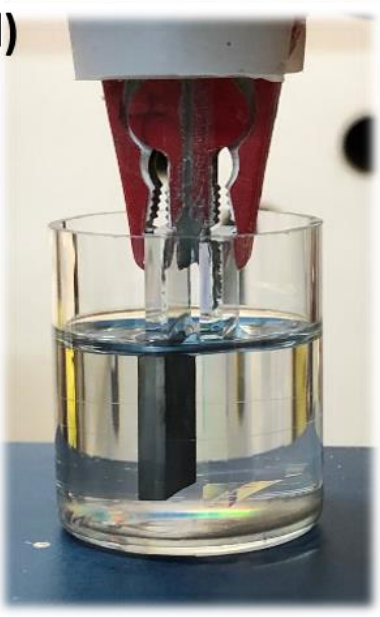

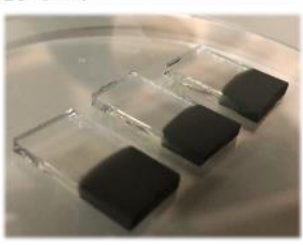

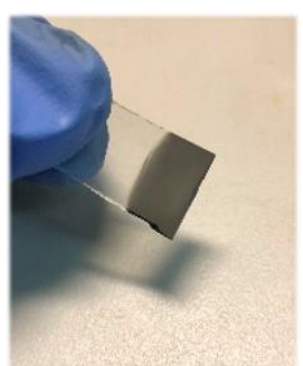

Figure 2. a) XRD patterns of FTO, pre-processed the bulk antimony crystals and SbFTO. b) XPS analysis of the surface and deeper levels of SbFTO after sputtering with Ar ions. The colors correspond to; green - O1s, blue - $\mathrm{Sb}^{\mathrm{v}}$, red $-\mathrm{Sb}^{\mathrm{III}}$, orange - $\mathrm{Sb}^{0}$. c) Structure of $\beta$ - 
antimony and picture of a 2D-Sb nanolayers toluene dispersion. d) Picture of the electrophoretic deposition of $\mathrm{Sb}$ on FTO substrates.

This technique is based on the phenomenon of electrophoresis, namely, the movement of colloidal particles upon creation of an electric field by applying a certain potential, and it offers the possibility to control film properties by manipulating parameters like deposition time, voltage or solvent [31]. Here, we will focus this work on the electrodes prepared at $300 \mathrm{~V}$ during 3 min of deposition, owing to the optimum photoelectrochemical performance (as shown later in the manuscript). EPD over fluorine-doped tin oxide (FTO) electrodes yield a homogeneous 2D-Sb coating of $2 \mu \mathrm{m}$ thickness (Figure S5).

The X-ray diffraction (XRD) pattern of the electrode is similar to that obtained for the preprocessed antimony crystals and nicely corresponds to the peaks observed for the $\beta$-antimony phase with crystal planes (012), (104), and (110) located at 28.5, 40 and $41.9^{\circ}$, respectively (Figure 2a) [32]. X-ray photoelectron spectroscopy (XPS) measurements indicate that the surface is composed mainly of antimony oxides with oxidation states of Sb III and V due to the thermal annealing carried out in order to improve the contact with the electrode [33]. Nevertheless, XPS depth profile up to $17.5 \mathrm{~nm}$ reveals that the bulk Sb is much less oxidized, showing the peak corresponding to metallic $\mathrm{Sb}(527.9 \mathrm{eV})$ in addition to the antimony oxides $\mathrm{Sb}_{2} \mathrm{O}_{3}(529.8 \mathrm{eV})$ and $\mathrm{Sb}_{2} \mathrm{O}_{5}(530.2 \mathrm{eV})$, which appear at lower binding energies compared to the surface level (530.5 and $530.9 \mathrm{eV}$, respectively). A peak corresponding to O1s was also observed at 531.9 and $531.5 \mathrm{eV}$ for the surface, and the deeper level, respectively (Figure 2b). Additionally, we performed the EPD of Sb flakes over $20 \mathrm{~nm} \mathrm{TiO}$-coated FTO electrodes [34]. $\mathrm{TiO}_{2}$ is a widely used semiconductor in photo-catalytic applications due to its low cost and its utilization in a photoelectrochemical cell has been widely reported [35]. Nevertheless, its wide band gap alongside its poor hole extraction kinetics hinder its capability to achieve a high current density upon illumination and therefore its optimal water splitting performance. Our 
research group and others showed recently the formation of $2 \mathrm{D} / 2 \mathrm{D}$ heterojunctions between a wide band gap semiconductor and low-dimensional pnictogens like phosphorene or 2D-Sb, where the intimate contact resulted in charge transfer, the quench of the electron-hole pairs recombination and consequently significant enhancement of the photocatalytic activity [3640]. Based on our previous results, and the predicted electrocatalytic activity of Sb [41], we decided to investigate the influence of the deposition of 2D-Sb flakes on $\mathrm{TiO}_{2}$ photoanodes and to evaluate its photoelectrochemical performance. XRD and XPS confirmed the successful coating of $\mathrm{TiO}_{2}$ electrodes. XRD patterns show the (101) crystal plane of the anatase- $\mathrm{TiO}_{2}$ at $25.2^{\circ}[42,43]$, as well as the contributions corresponding to $\mathrm{Sb}$, by the existence of diffraction peaks at $25.5,40$, and $41.9^{\circ}$ (Figure S6a). XPS shows the higher oxidation of the Sb surface compared to the inner levels, as proven by the peaks corresponding to $\mathrm{Sb}^{\mathrm{V}}$ and $\mathrm{Sb}^{\mathrm{III}}$ at 530.3 and $529.9 \mathrm{eV}$, respectively. After sputtering with Ar ions the binding energies of the $\mathrm{Sb}$ oxides remain in similar values and an additional chemical contribution that corresponds to metallic $\mathrm{Sb}$ can be observed at $528.9 \mathrm{eV}$. In both cases, another binding energy that belongs to O1s can be found at 531.2 and $530.9 \mathrm{eV}$ for the surface and the inner level (Figure S6b). The interaction between the $\mathrm{Sb}$ flakes and the $\mathrm{TiO}_{2}$ was further confirmed by UV-vis spectroscopy, by the enhanced light scattering for the $\mathrm{Sb}-\mathrm{TiO}_{2}$ electrode (Figure S7).

SEM images confirm the covering of the FTO and $\mathrm{TiO}_{2}$ surface by $2 \mathrm{D}-\mathrm{Sb}$ flakes of an approximate size of $200 \mathrm{~nm}$ (Figure 3, Figure S8). Additionally, XEDS imaging shows a homogeneous distribution of the different elements (Figure S9, S10) along the electrodes. 


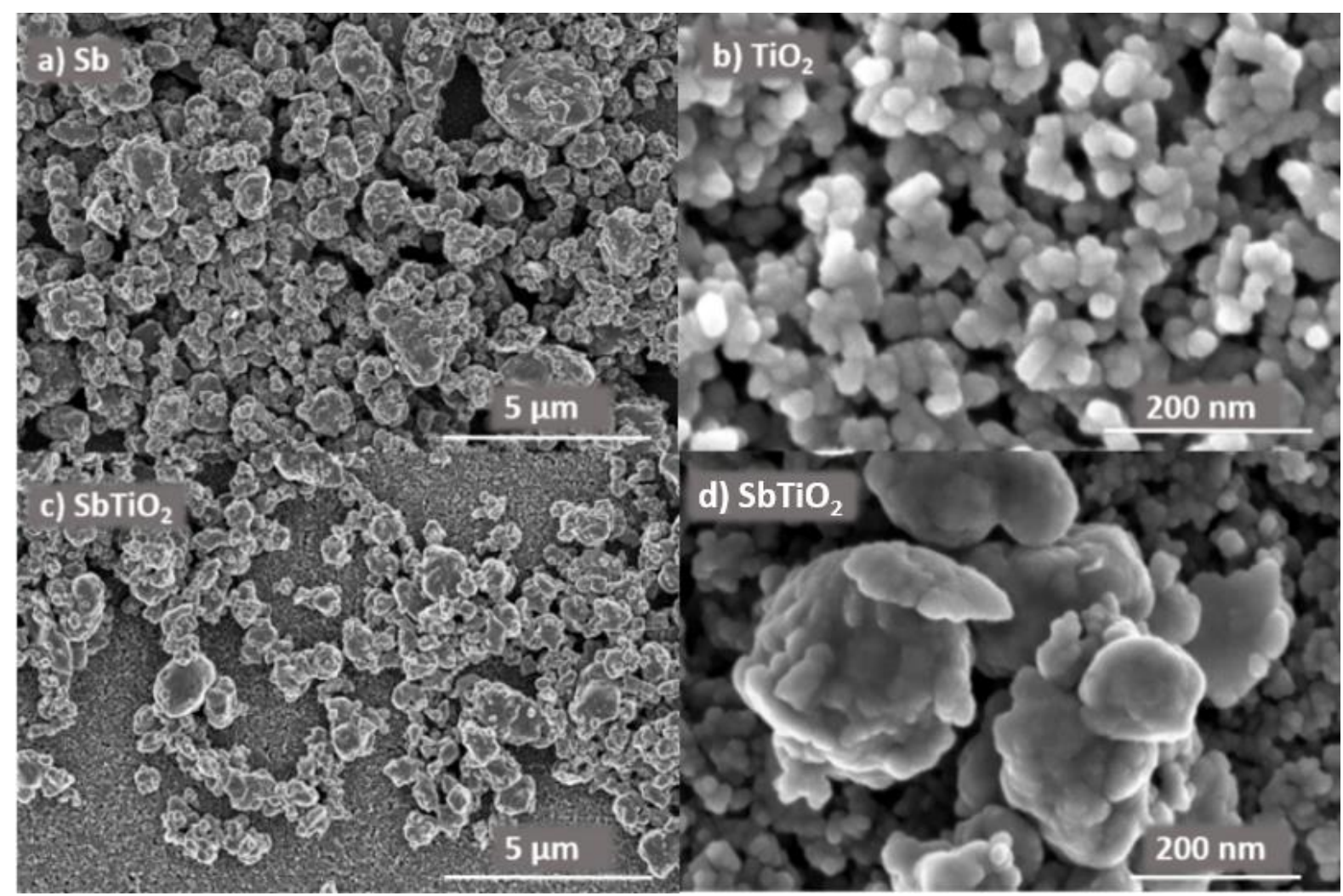

Figure 3. SEM images of FTO electrodes covered with a) $2 \mathrm{D}-\mathrm{Sb}$, b) $\mathrm{TiO}_{2}$ and c,d) $\mathrm{SbTiO}_{2}$.

\subsection{Photoelectrochemical activity}

The photoelectrochemical performance of the prepared electrodes was tested in a standard three electrodes photoelectrochemical cell (PEC) with an $\mathrm{Ag} / \mathrm{AgCl}$ reference electrode, $\mathrm{Pt}$ as counter electrode, in different electrolytes and upon 1 sun illumination $[44,45]$. The SbFTO electrodes prepared by deposition during 3 min compared to 1, 2, and 4 min show a slightly higher photocurrent in basic media $(\mathrm{KOH} 0.1 \mathrm{M}, \mathrm{pH}=13)$ (Figure S11a). Therefore, we decided to focus the study on electrodes prepared with deposition conditions of $3 \mathrm{~min}$ and $300 \mathrm{~V}$. SbFTO showed a higher photoelectrochemical performance in acid electrolyte (Figure S11b, Figure S12), reaching $4 \mu \mathrm{A} \mathrm{cm}^{-2}$ of stable current density upon illumination at $1.23 \mathrm{~V} v s$ RHE for the course of measurement. This fact could be due to the higher stability of the passivation layer of antimony oxides in acidic media, and partial dissolution of the antimony oxides layer into hydroxides [46]. The deposition of $\mathrm{Sb}$ flakes on $\mathrm{TiO}_{2}$ dramatically enhances the photoanodic 
performance, reaching an initial current of more than $250 \mu \mathrm{A} \mathrm{cm}^{-2}\left(v s 20 \mu \mathrm{A} \mathrm{cm}^{-2}\right.$ of bare $\mathrm{TiO}_{2}$ electrodes) in a basic media, $130 \mu \mathrm{A} \mathrm{cm}^{-2}$ in acidic electrolyte, and $100 \mu \mathrm{A} \mathrm{cm}^{-2}$ in neutral $\mathrm{pH}$ (Figure 4a, b). We want to note that, despite higher values have been reported in the state of the art of photoelectrochemical cells using materials such like perovskites,[47] bismuth vanadates $\left(\mathrm{BiVO}_{4}\right),[48,49]$ metal oxides,[50,51] carbon nitrides $\left(\mathrm{C}_{3} \mathrm{~N}_{4}\right)[52,53]$ and more (Table S1),[5457] the value reported here is considerably high for $\mathrm{TiO}_{2}$-based catalysts. Additionally, up to our knowledge this is the first time that antimonene is utilized in a photo-electrochemical cell and furthermore showing such a marked enhancement. However, the high solubility of the antimony oxide passivation layer causes the quick decrease of the photocurrent density. The photoelectrodes show wavelength-dependent activity, incident photon-to-current efficiency (IPCE) measurements show a value of $3.4 \%$ at $340 \mathrm{~nm}$ and response up to more than $400 \mathrm{~nm}$, confirming the improvement in the charge separation of the $\mathrm{TiO}_{2}$ electrodes (Figure 4c). Additionally, the utilization of a hole scavenger like triethanolamine (TEOA) improved substantially the stability of the photoelectrodes, reaching $220 \mu \mathrm{A} \mathrm{cm}^{-2}$ after 5 on/off cycles ( $v s$ $110 \mu \mathrm{A} \mathrm{cm}^{-2}$ without any hole scavenger, Figure S13), nevertheless the initial current does not differ from the one obtained in the absence of, implying the good charge separation efficiency and hole injection into the electrolyte for the water oxidation half-reaction. The higher photocurrent systematically measured with back illumination conditions reflect that electron transport, rather than hole transport, limits the performance of the $\mathrm{SbTiO}_{2}$ photoelectrode. The capability of the electrodes of efficiently separating electron-hole pairs was further investigated by measuring the open circuit voltage (Voc), where the $\mathrm{SbTiO}_{2}$ displayed a remarkable value of $-0.77 \mathrm{~V}$ ( $v s-0.15 \mathrm{~V}$ for bare $\mathrm{TiO}_{2}$ electrodes) (Figure $\left.4 \mathrm{~d}\right)$. 

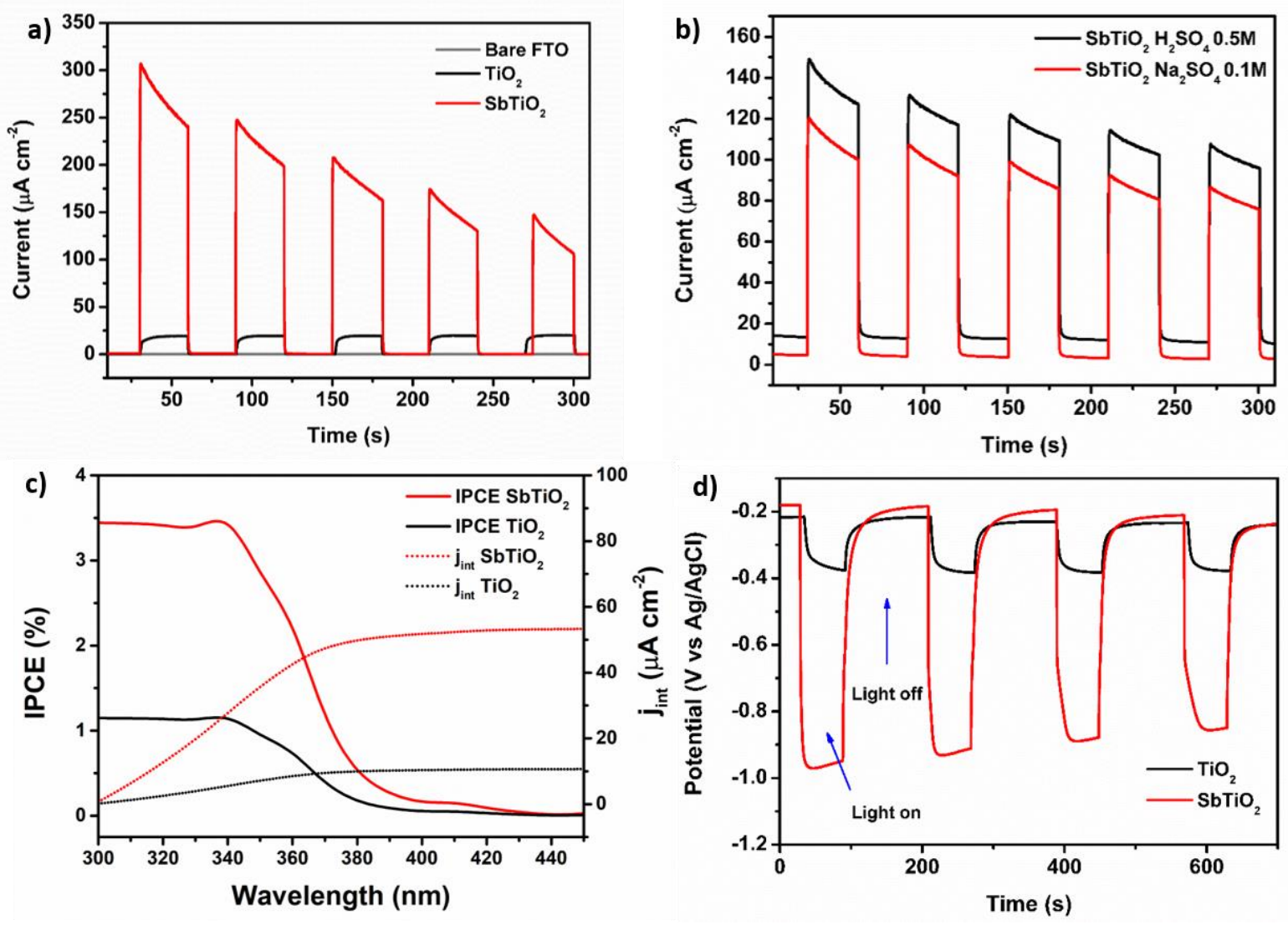

Figure 4. Photocurrent measurements for $\mathrm{SbTiO}_{2}$ electrodes in a) $\mathrm{KOH} 0.1 \mathrm{M}$, b) $\mathrm{H}_{2} \mathrm{SO}_{4} 0.5 \mathrm{M}$ and $\mathrm{Na}_{2} \mathrm{SO}_{4}$ 0.1M. c) Incident photon-to-current efficiency at $1.23 \mathrm{~V}$ vs RHE in a KOH $0.1 \mathrm{M}$ electrolyte. d) Open circuit voltage of $\mathrm{SbTiO}_{2}$ electrode.

Further mechanistic evaluation of the photoelectrodes was carried out by impedance spectroscopy (IS). We have studied the behavior of the $\mathrm{SbTiO}_{2}$ photoanode (compared to $\mathrm{TiO}_{2}$ reference) under different polarization conditions. The transport and recombination dynamics of the electrodes were determined under forward polarization (negative currents in the cyclic voltammograms, Figure S14), and the results clearly showed that at this regime, both conductivity and recombination dynamics were less favorable for PEC performance, compared to the reference $\mathrm{TiO}_{2}$ (Figure 5a, b). 

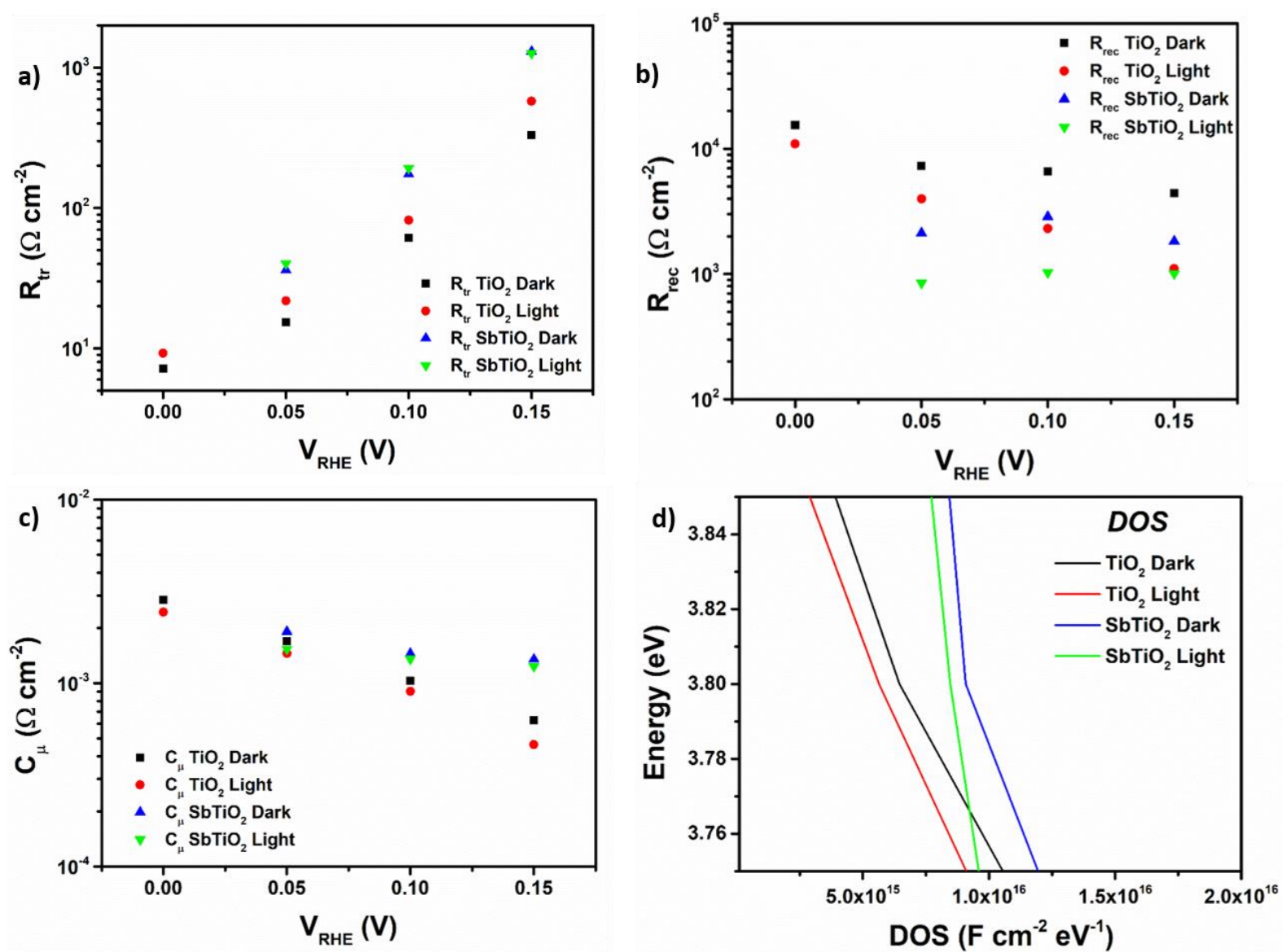

Figure 5. (a) Transport and (b) charge transfer resistances extracted from EIS analysis on $\mathrm{TiO}_{2}$ and $\mathrm{SbTiO}_{2}$ under dark and illumination conditions in the cathodic region, (c) Chemical capacitance and (d) the corresponding DOS extracted from IS at the cathodic region, as $\mathrm{C}=$ $\mathrm{e} \cdot \mathrm{DOS}$, where "e" is the elemental charge.

On the other hand, higher capacitance (chemical capacitance, $C_{\mu}$ ) was obtained for $\mathrm{SbTiO}_{2}$ (Figure 5c), which could be indicative of higher density of catalytic sites, if the density of states (DOS) is calculated from this chemical capacitance as $C_{\mu}=e D O S$, where $e$ is the elemental charge (Figure 5d). At reverse polarization (positive currents in the cyclic voltammograms, Figure S13), charge transfer resistance is lower for $\mathrm{SbTiO}_{2}$ (Figure 6a), in good agreement with the measured photocurrents shown in Figure 3a. At this anodic region, the capacitance (Figure 6b) is mainly dominated by the double layer capacitance $\left(20 \mu \mathrm{F} \mathrm{cm}^{2}\right.$ at the most anodic potentials). The flat-band potential and donor density of the films from were also determined 
by Mott-Schottky analysis, although these mesoporous films are not ideal for this type of analysis. Estimated values for the flat-band potential around $0.18 \mathrm{~V} v s$ RHE and a donor density of around $3 \times 10^{20} \mathrm{~cm}^{-3}$ were obtained for the reference $\mathrm{TiO}_{2}$ (Figure $\mathrm{S} 15 \mathrm{a}, \mathrm{b}$ ).
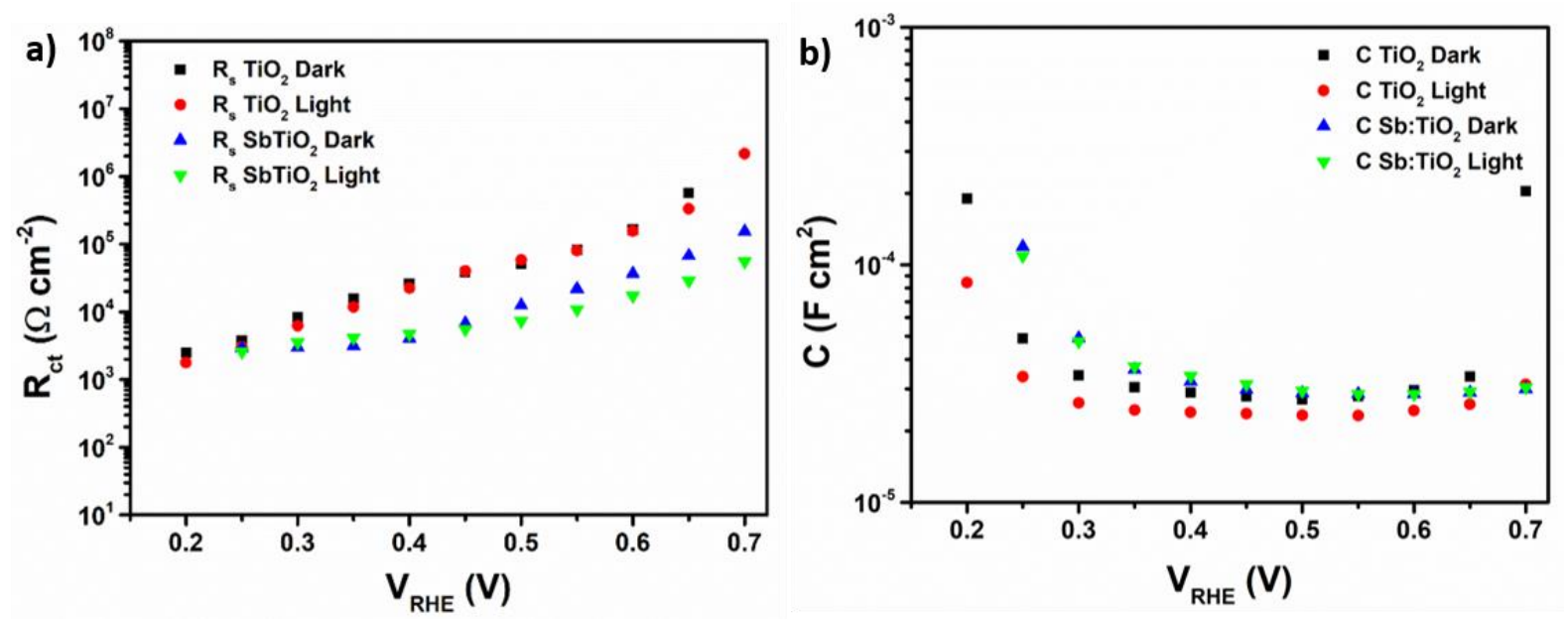

Figure 6. (a) Charge transfer resistance and (b) capacitance extracted for the analyzed samples in the anodic region.

On the other hand, a flat-band potential around $0.22 \mathrm{~V} v s$ RHE and a donor density of around $5 \times 10^{20} \mathrm{~cm}^{-3}$ were obtained for $\mathrm{SbTiO}_{2}$ doped (Figure S15c, d). These values are in good agreement with previous studies on $\mathrm{TiO}_{2}$ photoanodes [58,59]. It is clear that the deposition of Sb flakes anodically shifts the conduction band of $\mathrm{TiO}_{2}$ and slightly increases the carrier density. The energy diagram for both $\mathrm{TiO}_{2}$ and $\mathrm{SbTiO}_{2}$ was determined from optical and electronic characterization (Figure S16). Compared to the reference $\mathrm{TiO}_{2}, \mathrm{SbTiO}_{2}$ exhibits a valence band (VB) edge located at slightly lower energy respect to vacuum level, which thermodynamically favors the driving force of photo-generated holes for water oxidation.

\subsection{Photoelectrodes stability}

The stability of the photoelectrodes was evaluated by performing photoelectrochemical measurements for a prolonged period of time in both basic and acidic media. Despite the high initial photocurrent density, it decreases quickly with time, until reaching $40-50$ and $30 \mu \mathrm{A} \mathrm{cm}-$ ${ }^{2}$ in $\mathrm{KOH} 0.1 \mathrm{M}$ and $\mathrm{H}_{2} \mathrm{SO}_{4} 0.5 \mathrm{M}$ respectively after $10 \mathrm{~min}$, which then remains stable (Figure 
$\mathrm{S} 17 \mathrm{a}, \mathrm{b})$. The decay in the photoelectrochemical performance is attributed to the partial dissolution of the Sb layer in the electrolyte forming antimony hydroxides in basic media, as confirmed by the XRD patterns of the recycled electrode, where all the contributions corresponding to the $\beta$-antimony layer almost vanished (Figure 17c).

In the case of the measurement performed in acid electrolyte, where the system produced 0.03 $\mu$ mol $\mathrm{H}_{2}$ after $1 \mathrm{~h}$ (Figure S18) the 2D-Sb layer suffers less losses and still shows remaining XRD diffraction peaks of the initial $\beta$-antimony. Additionally, XPS in depth profile confirmed the presence of the same chemical states shown before PEC measurements (Figure S17d, S19).

\section{Conclusions}

Liquid phase exfoliation of antimony in toluene allows the formation of a suspension containing 2D-Sb nanolayers (200-400 $\mathrm{nm}$ in lateral dimensions) with a thickness of few nanometers ( $c a$. $4 \mathrm{~nm}$ ). This suspension is highly suitable to produce homogeneous and well-defined films with thickness of antimonene on FTO and $\mathrm{TiO}_{2}$-coated FTO using electrophoretic deposition.

The SbFTO electrodes prepared by deposition during $3 \mathrm{~min}$ and $300 \mathrm{~V}$ showed a higher photoelectrochemical performance in acid electrolyte, reaching $4 \mu \mathrm{A} \mathrm{cm}{ }^{-2}$ of stable current density upon illumination at $1.23 \mathrm{~V}$ vs RHE for the course of measurement. This is attributable to the higher stability of the passivation layer of antimony oxides in acidic media, and partial dissolution of the antimony oxides layer into hydroxides. Thus, the deposition of Sb flakes on $\mathrm{TiO}_{2}$ dramatically enhances the photoanodic performance, reaching an initial current of more than $250 \mu \mathrm{A} \mathrm{cm}^{-2}$ (vs $20 \mu \mathrm{A} \mathrm{cm}$ co $^{-2}$ bare $\mathrm{TiO}_{2}$ electrodes) in a basic medium, $130 \mu \mathrm{A} \mathrm{cm}^{-2}$ in acidic electrolyte, and $100 \mu \mathrm{A} \mathrm{cm}^{-2}$ in neutral $\mathrm{pH}$ with remarkable hole extraction kinetics as shown by the measurements performed in the presence of TEOA. Therefore, the so-formed $\mathrm{TiO}_{2}$-coated FTO films have shown promising activity as absorber and hole acceptor layer in a photoelectrochemical cell. The mechanistic evaluation of the $\mathrm{TiO}_{2}$-coated FTO photoelectrodes carried out by impedance spectroscopy shows that both conductivity and recombination 
dynamics in the cathodic region are less favorable for PEC performance, compared to the reference $\mathrm{TiO}_{2}$. Nevertheless, the deposition of Sb flakes anodically shifts the conduction band of $\mathrm{TiO}_{2}$ and slightly increases the carrier density resulting in improved optical absorption and charge separation properties.

The energy diagram for both $\mathrm{TiO}_{2}$ and $\mathrm{SbTiO}_{2}$ determined from optical and electronic characterization shows a valence band edge located at slightly lower energy respect to vacuum level, which thermodynamically favors the driving force of photo-generated holes for water oxidation.

\section{Corresponding Author}

Sixto Giménez - E-Mail: sjulia@ @ca.uji.es

Menny Shalom - E-Mail: mennysh@bgu.ac.il

Félix Zamora - E-Mail: felix.zamora@uam.es

\section{Acknowledgements}

Jesús Barrio and Carlos Gibaja contributed equally to this work. This research was funded by the Israel Science Foundation (ISF), grant No. 1161/17, and supported by the Minerva Center No. 117873. SG acknowledges financial support from the Ministerio de Ciencia, Innovación y Universidades of Spain (ENE2017-85087-C3-1-R, MAT2016-77608-C3-1-P and PCI2018093081).

\section{References}

[1] A.K. Geim, K.S. Novoselov, The rise of graphene, Nat. Mater. 6 (2007) 183-191. https://doi.org/10.1038/nmat1849.

[2] M. Chhowalla, H.S. Shin, G. Eda, L.-J. Li, K.P. Loh, H. Zhang, The chemistry of twodimensional layered transition metal dichalcogenide nanosheets., Nat. Chem. 5 (2013) 263-75. https://doi.org/10.1038/nchem.1589.

[3] B. Anasori, Y. Xie, M. Beidaghi, J. Lu, B. C. Hosler, L. Hultman, P. R. C. Kent, Y. Gogotsi, M. W. Barsoum, Two-Dimensional, Ordered, Double Transition Metals Carbides (MXenes), ACS Nano. 9 (2015) 9507-9516. https://doi.org/10.1021/acsnano.5b03591.

[4] J. Zhang, Y. Chen, X. Wang, Two-dimensional covalent carbon nitride nanosheets: 
synthesis, functionalization, and applications, Energy Environ. Sci. 8 (2015) 30923108. https://doi.org/10.1039/C5EE01895A.

[5] X. Jiang, Q. Weng, X. Wang, X. Li, J. Zhang, D. Golberg, Y. Bando, Recent Progress on Fabrications and Applications of Boron Nitride Nanomaterials : A Review, J. Mater. Sci. Technol. 31 (2015) 589-598. https://doi.org/10.1016/j.jmst.2014.12.008.

[6] H. Liu, A. T. Neal, Z. Zhu, Z. Luo, X. Xu, D. Tománek, P. D. Ye, Phosphorene: An Unexplored 2D Semiconductor with a High Hole Mobility, ACS Nano. 8 (2014) 40334041. https://doi.org/10.1021/nn501226z.

[7] A. Gupta, T. Sakthivel, S. Seal, Recent development in 2D materials beyond graphene, Prog. Mater. Sci. 73 (2015) 44-126. https://doi.org/10.1016/j.pmatsci.2015.02.002.

[8] P. Ares, F. Aguilar-Galindo, D. Rodríguez-San-Miguel, D.A. Aldave, S. Díaz-Tendero, M. Alcamí, F. Martín, J. Gómez-Herrero, F. Zamora, Mechanical Isolation of Highly Stable Antimonene under Ambient Conditions, Adv. Mater. 28 (2016) 6332-6336. https://doi.org/10.1002/adma.201602128.

[9] A.M.L. Marzo, R. Gusmão, Z. Sofer, M. Pumera, Towards Antimonene and 2D Antimony Telluride through Electrochemical Exfoliation, Chem. - A Eur. J. n/a (2020). https://doi.org/10.1002/chem.201905245.

[10] C. Gibaja, D. Rodriguez-San-Miguel, P. Ares, J. Gómez-Herrero, M. Varela, R. Gillen, J. Maultzsch, F. Hauke, A. Hirsch, G. Abellán, F. Zamora, Few-Layer Antimonene by Liquid-Phase Exfoliation, Angew. Chem. Int. Ed. 55 (2016) 14345-14349. https://doi.org/10.1002/anie.201605298.

[11] J. Ji, X. Song, J. Liu, Z. Yan, C. Huo, S. Zhang, M. Su, L. Liao, W. Wang, Z. Ni, Y. Hao, H. Zeng, Two-dimensional antimonene single crystals grown by van der Waals epitaxy, Nat. Commun. 7 (2016) 13352. https://doi.org/10.1038/ncomms13352.

[12] S. Zhang, M. Xie, F. Li, Z. Yan, Y. Li, E. Kan, W. Liu, Z. Chen, H. Zeng, Semiconducting Group 15 Monolayers: A Broad Range of Band Gaps and High Carrier Mobilities, Angew. Chem. Int. Ed. 55 (2016) 1666-1669. https://doi.org/10.1002/anie.201507568.

[13] P. Ares, J.J. Palacios, G. Abellán, J. Gómez-Herrero, F. Zamora, Recent Progress on Antimonene: A New Bidimensional Material, Adv. Mater. 30 (2018) 1703771. https://doi.org/10.1002/adma.201703771.

[14] J. Sturala, Z. Sofer, M. Pumera, Chemistry of Layered Pnictogens: Phosphorus, Arsenic, Antimony, and Bismuth, Angew. Chem. Int. Ed. 58 (2019) 7551-7557. https://doi.org/10.1002/anie.201900811.

[15] E. Martínez-Periñán, M.P. Down, C. Gibaja, E. Lorenzo, F. Zamora, C.E. Banks, Antimonene: A Novel 2D Nanomaterial for Supercapacitor Applications, Adv. Energy Mater. 8 (2018) 1702606. https://doi.org/10.1002/aenm.201702606.

[16] V. Lloret, M.Á. Rivero-Crespo, J.A. Vidal-Moya, S. Wild, A. Doménech-Carbó, B.S.J. Heller, S. Shin, H.-P. Steinrück, F. Maier, F. Hauke, M. Varela, A. Hirsch, A. LeyvaPérez, G. Abellán, Few layer 2D pnictogens catalyze the alkylation of soft nucleophiles with esters, Nat. Commun. 10 (2019) 509. https://doi.org/10.1038/s41467-018-080633.

[17] C. Gibaja, M. Assebban, I. Torres, M. Fickert, R. Sanchis-Gual, I. Brotons, W.S. Paz, J.J. Palacios, E.G. Michel, G. Abellán, F. Zamora, Liquid phase exfoliation of antimonene: systematic optimization, characterization and electrocatalytic properties, J. Mater. Chem. A. 7 (2019) 22475-22486. https://doi.org/10.1039/C9TA06072C.

[18] Q. Xiao, C.-X. Hu, H.-R. Wu, Y.-Y. Ren, X.-Y. Li, Q.-Q. Yang, G.-H. Dun, Z.-P. Huang, Y. Peng, F. Yan, Q. Wang, H.-L. Zhang, Antimonene-based flexible photodetector, Nanoscale Horizons. 5 (2020) 124-130. https://doi.org/10.1039/C9NH00445A.

[19] C.C. Mayorga-Martinez, R. Gusmão, Z. Sofer, M. Pumera, Pnictogen-Based 
Enzymatic Phenol Biosensors: Phosphorene, Arsenene, Antimonene, and Bismuthene, Angew. Chem. Int. Ed. 58 (2019) 134-138. https://doi.org/10.1002/anie.201808846.

[20] T. García-Mendiola, C. Gutiérrez-Sánchez, C. Gibaja, I. Torres, C. Busó-Rogero, F. Pariente, J. Solera, Z. Razavifar, J. J. Palacios, F. Zamora, E. Lorenzo,

Functionalization of a Few-Layer Antimonene with Oligonucleotides for DNA

Sensing, ACS Appl. Nano Mater. 3 (2020) 3625-3633.

https://doi.org/10.1021/acsanm.0c00335.

[21] I. Horcas, R. Fernández, J.M. Gómez-Rodríguez, J. Colchero, J. Gómez-Herrero, A.M. Baro, $<\operatorname{scp}>$ WSXM $</$ scp $>$ : A software for scanning probe microscopy and a tool for nanotechnology, Rev. Sci. Instrum. 78 (2007) 013705.

https://doi.org/10.1063/1.2432410.

[22] P. Nemes-Incze, Z. Osváth, K. Kamarás, L.P. Biró, Anomalies in thickness measurements of graphene and few layer graphite crystals by tapping mode atomic force microscopy, Carbon N. Y. 46 (2008) 1435-1442. https://doi.org/10.1016/j.carbon.2008.06.022.

[23] F. Fabregat-Santiago, G. Garcia-Belmonte, J. Bisquert, P. Bogdanoff, A. Zaban, MottSchottky Analysis of Nanoporous Semiconductor Electrodes in Dielectric State Deposited on SnO[sub 2](F) Conducting Substrates, J. Electrochem. Soc. 150 (2003) E293. https://doi.org/10.1149/1.1568741.

[24] Y. Ma, J. Han, M. Wang, X. Chen, S. Jia, Electrophoretic deposition of graphene-based materials: A review of materials and their applications, J. Mater. 4 (2018) 108-120. https://doi.org/10.1016/J.JMAT.2018.02.004.

[25] J. Xu, M. Shalom, Electrophoretic Deposition of Carbon Nitride Layers for Photoelectrochemical Applications, ACS Appl. Mater. Interfaces. 8 (2016) 1305813063. https://doi.org/10.1021/acsami.6b02853.

[26] I. Hod, W. Bury, D.M. Karlin, P. Deria, C.-W. Kung, M.J. Katz, M. So, B. Klahr, D. Jin, Y.-W. Chung, T.W. Odom, O.K. Farha, J.T. Hupp, Directed Growth of Electroactive Metal-Organic Framework Thin Films Using Electrophoretic Deposition, Adv. Mater. 26 (2014) 6295-6300. https://doi.org/10.1002/adma.201401940.

[27] R. Ifraemov, R. Shimoni, W. He, G. Peng, I. Hod, A metal-organic framework film with a switchable anodic and cathodic behaviour in a photo-electrochemical cell, J. Mater. Chem. A. 7 (2019) 3046-3053. https://doi.org/10.1039/C8TA10483B.

[28] J. M. Rotter, S. Weinberger, J. Kampmann, T. Sick, M. Shalom, T. Bein, D. D. Medina, Covalent Organic Framework Films through Electrophoretic DepositionCreating Efficient Morphologies for Catalysis, Chem. Mater. 31 (2019) 10008-10016. https://doi.org/10.1021/acs.chemmater.9b02286.

[29] A. Salant, M. Shalom, I. Hod, A. Faust, A. Zaban, U. Banin, Quantum Dot Sensitized Solar Cells with Improved Efficiency Prepared Using Electrophoretic Deposition, ACS Nano. 4 (2010) 5962-5968. https://doi.org/10.1021/nn1018208.

[30] M. Volokh, M. Diab, K. Flomin, T. Mokari, Electrophoretic deposition of single-source precursors as a general approach for the formation of hybrid nanorod array heterostructures, J. Colloid Interface Sci. 515 (2018) 221-231. https://doi.org/10.1016/J.JCIS.2018.01.030.

[31] L. Besra, M. Liu, A review on fundamentals and applications of electrophoretic deposition (EPD), Prog. Mater. Sci. 52 (2007) 1-61. https://doi.org/10.1016/J.PMATSCI.2006.07.001.

[32] W. Tian, S. Zhang, C. Huo, D. Zhu, Q. Li, L. Wang, X. Ren, L. Xie, S. Guo, P. K. Chu, H. Zeng, K. Huo, Few-Layer Antimonene: Anisotropic Expansion and Reversible Crystalline-Phase Evolution Enable Large-Capacity and Long-Life Na-Ion Batteries, ACS Nano. 12 (2018) 1887-1893. https://doi.org/10.1021/acsnano.7b08714.

[33] A.A. Kistanov, Y. Cai, D.R. Kripalani, K. Zhou, S. V Dmitriev, Y.-W. Zhang, A first- 
principles study on the adsorption of small molecules on antimonene: oxidation tendency and stability, J. Mater. Chem. C. 6 (2018) 4308-4317.

https://doi.org/10.1039/C8TC00338F.

[34] Y. Amao, Y. Yamada, K. Aoki, Preparation and properties of dye-sensitized solar cell using chlorophyll derivative immobilized TiO2 film electrode, J. Photochem.

Photobiol. A Chem. 164 (2004) 47-51.

https://doi.org/10.1016/J.JPHOTOCHEM.2003.11.011.

[35] T. Ochiai, A. Fujishima, Photoelectrochemical properties of $\mathrm{TiO} 2$ photocatalyst and its applications for environmental purification, J. Photochem. Photobiol. C Photochem.

Rev. 13 (2012) 247-262. https://doi.org/10.1016/J.JPHOTOCHEMREV.2012.07.001.

[36] J. Low, J. Yu, M. Jaroniec, S. Wageh, A.A. Al-Ghamdi, Heterojunction Photocatalysts, Adv. Mater. 29 (2017) 1601694. https://doi.org/10.1002/adma.201601694.

[37] J. Barrio, C. Gibaja, J. Tzadikov, M. Shalom, F. Zamora, 2D/2D Graphitic Carbon Nitride/Antimonene Heterostructure: Structural Characterization and Application in Photocatalysis, Adv. Sustain. Syst. 3 (2019) 1800138.

https://doi.org/10.1002/adsu.201800138.

[38] J. Ran, W. Guo, H. Wang, B. Zhu, J. Yu, S.-Z. Qiao, Metal-Free 2D/2D Phosphorene/g-C3N4 Van der Waals Heterojunction for Highly Enhanced VisibleLight Photocatalytic H2 Production, Adv. Mater. 30 (2018) 1800128. https://doi.org/10.1002/adma.201800128.

[39] Y. Xu, X. Wang, M. Jin, K. Kempa, L. Shui, Water Splitting Performance Enhancement of the TiO 2 Nanorod Array Electrode with Ultrathin Black Phosphorus Nanosheets, ChemElectroChem. 7 (2020) 96-104. https://doi.org/10.1002/celc.201901456.

[40] Z. Zhao, S. Hong, C. Yan, C. Choi, Y. Jung, Y. Liu, S. Liu, X. Li, J. Qiu, Z. Sun, Efficient visible-light driven $\mathrm{N} 2$ fixation over two-dimensional $\mathrm{Sb} / \mathrm{TiO} 2$ composites, Chem. Commun. 55 (2019) 7171-7174. https://doi.org/10.1039/C9CC02291K.

[41] R. Gusmão, Z. Sofer, D. Bouša, M. Pumera, Pnictogen (As, Sb, Bi) Nanosheets for Electrochemical Applications Are Produced by Shear Exfoliation Using Kitchen Blenders, Angew. Chem. Int. Ed. 56 (2017) 14417-14422. https://doi.org/10.1002/anie.201706389.

[42] C.-T. Li, S.-R. Li, L.-Y. Chang, C.-P. Lee, P.-Y. Chen, S.-S. Sun, J.-J. Lin, R. Vittal, K.-C. Ho, Efficient titanium nitride/titanium oxide composite photoanodes for dyesensitized solar cells and water splitting, J. Mater. Chem. A. 3 (2015) 4695-4705. https://doi.org/10.1039/C4TA05606J.

[43] Y. Qu, C. Sun, G. Sun, X. Kong, W. Zhang, Preparation, characterization, and kinetic and thermodynamic studies of mixed-phase $\mathrm{TiO} 2$ nanoparticles prepared by detonation method, Results Phys. 6 (2016) 100-106. https://doi.org/10.1016/J.RINP.2016.02.006.

[44] M. Grätzel, Photoelectrochemical cells, Nature. 414 (2001) 338-344. https://doi.org/10.1038/35104607.

[45] M. Volokh, G. Peng, J. Barrio, M. Shalom, Carbon Nitride Materials for Water Splitting Photoelectrochemical Cells, Angew. Chem. Int. Ed. 58 (2019) 6138-6151. https://doi.org/10.1002/anie.201806514.

[46] K. Oorts, E. Smolders, F. Degryse, J. Buekers, G. Gascó, G. Cornelis, J. Mertens, Solubility and Toxicity of Antimony Trioxide (Sb2O3) in Soil, Environ. Sci. Technol. Technol. 42 (2008) 4378-4383. https://doi.org/10.1021/es703061t.

[47] I. Poli, U. Hintermair, M. Regue, S. Kumar, E. V Sackville, J. Baker, T.M. Watson, S. Eslava, P.J. Cameron, Graphite-protected $\mathrm{CsPbBr} 3$ perovskite photoanodes functionalised with water oxidation catalyst for oxygen evolution in water, Nat. Commun. 10 (2019) 2097. https://doi.org/10.1038/s41467-019-10124-0.

[48] D. Cardenas-Morcoso, R. Ifraemov, M. García-Tecedor, I. Liberman, S. Gimenez, I. 
Hod, A metal-organic framework converted catalyst that boosts photo-electrochemical water splitting, J. Mater. Chem. A. 7 (2019) 11143-11149.

https://doi.org/10.1039/C9TA01559K.

[49] F.F. Abdi, L. Han, A.H.M. Smets, M. Zeman, B. Dam, R. van de Krol, Efficient solar water splitting by enhanced charge separation in a bismuth vanadate-silicon tandem photoelectrode., Nat. Commun. 4 (2013) 2195. https://doi.org/10.1038/ncomms3195.

[50] B.D. Alexander, P.J. Kulesza, I. Rutkowska, R. Solarska, J. Augustynski, Metal oxide photoanodes for solar hydrogen production, J. Mater. Chem. 18 (2008) 2298-2303. https://doi.org/10.1039/B718644D.

[51] Š. Hajduk, S.P. Berglund, M. Podlogar, G. Dražić, F.F. Abdi, Z.C. Orel, M. Shalom, Conformal Carbon Nitride Coating as an Efficient Hole Extraction Layer for ZnO Nanowires-Based Photoelectrochemical Cells, Adv. Mater. Interfaces. 4 (2017) 1700924. https://doi.org/10.1002/admi.201700924.

[52] N. Karjule, J. Barrio, L. Xing, M. Volokh, M. Shalom, Highly Efficient Polymeric Carbon Nitride Photoanode with Excellent Electron Diffusion Length and Hole Extraction Properties, Nano Lett. (2020) https://doi.org/10.1021/acs.nanolett.0c01484.

[53] N. Karjule, J. Barrio, J. Tzadikov, M. Shalom, Electronic Structure Engineering of Carbon Nitride Materials by Using Polycyclic Aromatic Hydrocarbons, Chem. - A Eur. J. 26 (2020) 6622-6628. https://doi.org/10.1002/chem.201905875.

[54] Z. Li, H. Qiao, Z. Guo, X. Ren, Z. Huang, X. Qi, S.C. Dhanabalan, J.S. Ponraj, D. Zhang, J. Li, J. Zhao, J. Zhong, H. Zhang, High-Performance Photo-Electrochemical Photodetector Based on Liquid-Exfoliated Few-Layered InSe Nanosheets with Enhanced Stability, Adv. Funct. Mater. 28 (2018) 1705237. https://doi.org/10.1002/adfm.201705237.

[55] Z. Huang, W. Han, H. Tang, L. Ren, D.S. Chander, X. Qi, H. Zhang, Photoelectrochemical-type sunlight photodetector based on $\mathrm{MoS}_{2}$ /graphene heterostructure, 2D Mater. 2 (2015) 035011. https://doi.org/10.1088/2053$1583 / 2 / 3 / 035011$.

[56] Z. Xie, C. Xing, W. Huang, T. Fan, Z. Li, J. Zhao, Y. Xiang, Z. Guo, J. Li, Z. Yang, B. Dong, J. Qu, D. Fan, H. Zhang, Ultrathin 2D Nonlayered Tellurium Nanosheets: Facile Liquid-Phase Exfoliation, Characterization, and Photoresponse with High Performance and Enhanced Stability, Adv. Funct. Mater. 28 (2018) 1705833. https://doi.org/10.1002/adfm.201705833.

[57] C. Xing, W. Huang, Z. Xie, J. Zhao, D. Ma, T. Fan, W. Liang, Y. Ge, B. Dong, J. Li, H. Zhang, Ultrasmall Bismuth Quantum Dots: Facile Liquid-Phase Exfoliation, Characterization, and Application in High-Performance UV-Vis Photodetector, ACS Photonics. 5 (2017) 621-629. https://doi.org/10.1021/acsphotonics.7b01211.

[58] M.N. Shaddad, D. Cardenas-Morcoso, M. García-Tecedor, F. Fabregat-Santiago, J. Bisquert, A. M. Al-Mayouf, S. Gimenez, TiO2 Nanotubes for Solar Water Splitting: Vacuum Annealing and Zr Doping Enhance Water Oxidation Kinetics, ACS Omega. 4 (2019) 16095-16102. https://doi.org/10.1021/acsomega.9b02297.

[59] Y. Liang, T. Tsubota, L. P. A. Mooij, R. van de Krol, Highly Improved Quantum Efficiencies for Thin Film BiVO4 Photoanodes, J. Phys. Chem. C. 115 (2011) 1759417598. https://doi.org/10.1021/jp203004v. 